Canadian Journal of Family and Youth, 10(2), 2018, pp 51-66

ISSN 1718-9748 (c) University of Alberta

http://ejournals.library.ualberta.ca/index/php/cjfy

\title{
"I Never Read Anything Like That Before:” Mapping the Identities of Blackfoot Readers
}

\author{
Erin Spring and Andrea True Joy Fox
}

\begin{abstract}
Our research emerges out of a concern that Indigenous readers, generally speaking, are not having opportunities to read and discuss culturally relevant fiction. Children's literature and reader response scholarship does not fully engage with what Indigenous voices could bring to our understanding of young people's responses to and engagement with fiction. We are currently conducting a community-based, participatory project with Blackfoot First Nations young adults who live on the Kainai Blood Reserve in southern Alberta. We are looking at the ways in which our participants perceive of and represent their social, cultural and place-based identities within and beyond the text. Our participants are reading and discussing several Indigenous texts, including a graphic novel set on their reserve. We are interested in the ways in which these readers reflect on their identities while discussing culturally relevant fiction, within reading discussion groups and the creation of journals (comprised of visual responses, such as maps, sketches, and photos). Within this article, we share how using culturally relevant and local, place-based fiction is spurring Blackfoot youth to have discussions about their identities within and beyond the text. We suggest that these methodological approaches are empowering the Blackfoot youth to develop their own self-representations by relating these stories to their own lives, including their memories of growing up on a reserve. In positioning our participants as experts in their own cultures and lived experiences, they are visualizing their own diversity, complexity and importance in the world.
\end{abstract}

Erin Spring is an Assistant Professor with the Werklund School of Education, University of Calgary. Her research interests relate to children's literature, reading, identity, literacy, qualitative research, youth studies, and place and space. Major publications include: Spring, E. (2017). Without Manifest, none of the book would have happened: place, identity, and the positioning of Canadian adolescent readers as literary critics. Children's Literature in Education, 1-18; Spring, E. (2016). The experiences of two migrant readers: freedom, restriction, and the navigation of adolescent space. Jeunesse: Young People, Texts, Cultures, 8(1), 227-247; and Spring, E. (2016). Where are you from?: locating the young adult self within and beyond the text. Children's Geographies, 14(3), 356-371.

Andrea True Joy Fox (B.A., B.Ed.) is the District Principal of First Nations, Metis, and Inuit Education, Lethbridge School District No. 51. Possessing the Blackfoot name "Pi’kssipitaakii," which translates to Bird Old Woman, Andrea grew up in Kainai, the Blood Tribe where she is from. She has had many diverse experiences within the world of education. As an educator, she is especially passionate about developing strong partnerships between Indigenous and non-Indigenous communities in the areas of the arts, culture and education, in order to increase the awareness and understandings of Truth and Reconciliation. She is passionate about the healing process that the arts nurture in the Indigenous community. Andrea deeply cares about the teacher-student relationship, recognizing relationships and trust are foundational for student well-being and success. Andrea is currently completing her MEd in Educational Leadership at the University of Lethbridge. 
Spring and Fox

\section{Introduction}

On a hot day in June 2017, a group of Blackfoot middle-school aged students gathered in a classroom on the Kainai Blood reserve in southern Alberta, Canada, to read aloud monologues they had written about influential female figures in their lives. They took turns sharing stories of their mothers, grandmothers, aunties, sisters, cousins and neighbours. These personal narratives were prompted by a shared reading of Sherman Alexie's (2012) The Absolutely True Diary of a Part-time Indian, which tells the story of Junior, whose grandmother is killed by a drunk driver on the Spokane Indian reservation near Washington. Our writing celebration was the culmination of a two-year collaborative project between Andrea True Joy Fox, a Blackfoot educator and graduate student in the University of Lethbridge’s (U of L) Faculty of Education, and Erin Spring, a settler and postdoctoral scholar with the Institute for Child and Youth Studies (I-CYS) at the $\mathrm{U}$ of $\mathrm{L}$.

Within this chapter, we reflect primarily on the methodological design of our project, which drew on participatory approaches such as reading discussion groups, journaling, artwork and land-based field trips, to foreground and underscore the voices of Blackfoot youth. We sought to understand what it is like for these readers to be young people living in this particular place, and how and if the act of reading culturally-relevant fiction incited them to reflect on their identities within and beyond the text. By encouraging the youth to share their experiences of the world in critical and creative ways, our approach affirmed their agency. In turn, we argue that youth self-determination and an awareness of identity can foster belonging, wellbeing, and resilience. This recognition chimes with Hauge's assertion that civic engagement reinforces “social relationships and public participation” (see Hauge in this volume). 


\section{Imagining a Collaborative Space}

Ongoing conversations about the intersections between reading and identity were the impetus for our decision to collaborate on a research project. Erin's doctoral research considered the ways in which teenagers, including migrant youth, articulated their place-identities through reading, writing, and art (Spring, 2015; Spring, 2016; Spring, 2017). In September 2014, she moved to Treaty 7 territory, spanning a large part of contemporary southwest Alberta, to begin her fellowship with I-CYS. While the city of Lethbridge has a vibrant urban Indigenous community, it is also in close proximity to the Kainai Blood Reserve, which is the largest reserve in Canada and the second most populous. In Lethbridge, the high population of Indigenous people uniquely shapes issues of shared space. As a settler scholar visiting this territory, with interests in the interconnections between land and identity, it became evident that an understanding of young people in this precise geography required a consideration of Blackfoot ways of knowing. As a teacher working on reserve, Andrea is particularly cognizant of encouraging her students to express themselves and their cultures through arts-based methods. Her pedagogical approach across the curriculum positions young people as experts of their own stories, experiences and cultural perspectives. In her classroom, students feel safe creating and sharing their narratives. As a result, they understand that they are important contributors to the various communities of which they are part, within and beyond classroom walls. Despite their cultural differences, Andrea and Erin arrived at this project with numerous shared beliefs about education, literacy and the need for cross-cultural dialogue and reconciliation.

Specifically, though, imagining our project began as a shared concern that Indigenous young people in Canada do not have sufficient opportunities to read culturally relevant fiction, and to respond in ways that feel most suitable to their experiences and cultural worldviews 
(Bradford, 2007, 2010; Korteweg, Gonzalez \& Guillet, 2010; L’Hirondelle Hill \& McCall, 2015;

Vowel, 2016). Andrea felt that her students were not necessarily connecting with the material found in the school library, most of which showcased experiences and worldviews unlike their own (Godinho et al., 2014; Wiltse, 2015; Yoon et al., 2010). Our early conversations confirmed our shared belief that stories and storytelling are vital to the process of making and transforming identities, especially among the young. If youth do not see themselves within the texts they read, there is a missed opportunity for critical conversations to occur about what it means to be young people in particular spaces and contexts. During these early conversations, the Truth and Reconciliation Commission (TRC, 2015) simultaneously released its final report, which calls for ways of integrating Indigenous knowledge and teaching methods into classrooms, as well as for building student capacity for intercultural understanding. From its inception, then, our project has been about creating an opportunity for intercultural and cross-cultural dialogue about and with young people. A collaborative approach has, we believe, the potential to facilitate change in the era of reconciliation, not only in the lives of the young but in the forms of respectful engagement that universities can foster with the wider community, including schools. Rather than being an obstacle, our cross-cultural approach has offered a critical space for the recognition, renegotiation, and reconciliation of a series of identities and ideas.

\section{Capturing the Process of Youth Identity}

Before outlining our research design, we draw attention to the theories of reading as a transaction (Rosenblatt, 1978) and place as a bundle of trajectories (Massey, 2005), as these concepts set the stage for how we conceptualize identity. Firstly, our project positions reading as a social event that is created through a transaction, or exchange, between readers and a text. Rather than conceptualizing the process as a solitary pursuit, reader-response scholar Louise 
Rosenblatt (1978) suggests that readers actively create meaning as they engage with the text as well as with each other. While we might read a text linearly, our reflections are constantly in motion. We bring our experiences of the world to our reading of the text, and through this encounter, any prior knowledge is changed: A new meaning is created. It is a transactional process in that the event results in the transformation of both reader and text. Because readers' ideas are inevitably articulated as well as changed in the transaction of reading, we can trace their identity development through their multimodal responses to and creation of a range of texts. Additionally, encountering the identities of others, and having conversations about their varying trajectories, can change a reader's own perspective. A social, spatial conceptualization of reading prompted us to ask: What evidence would we be able to find of the identities of our participants through their responses to and creation of a range of texts? Which stories would they share? Cultural geographer Doreen Massey’s (1991, 2005) conceptualization of time-space is likewise founded on the idea that place is created in the moment when various trajectories or ‘stories’ meet-up. Rather than representing place as static, as a surface to be covered or an area to be enclosed by a map, Massey suggests that space should be understood as dynamic, formed by the collision of different trajectories. This aligns with how many Indigenous communities imagine place and space. Each contributor to place is coming from somewhere, and is going somewhere else, through a range of temporal and spatial scales. Positioning identity as a convergence of trajectories, or as encounters framed by stories that align - even if momentarily foregrounds the socio-cultural influences that shape young people’s identity development, allowing for a more holistic understanding of their lives to surface. Numerous scholars draw on Massey to explore the links between place-based approaches to literacy and identity (Comber, 2013; 2016; Spring, 2015; 2016; 2017). 
Spring and Fox

Within this paper, we position identity not as a static construct, or a linear process that is achieved in stages, but rather as something that changes over time, across space, and through a range of experiences (see also Hogue and Forrest in this volume; Breakwell, 1986; Cuba \& Hummon, 1993; Dixon \& Durrheim, 2000). Identity is always in the process of being made. We argue that understanding the identities of young people requires a consideration of various determinants, as well as an acknowledgement that these factors (families, communities, peers, places, etc.) are continually transacting with one another, resulting in the likelihood of change in addition to continuity (Comber, 2013; Mills et al., 2013; Wiltse, 2015). Through the narratives that our participants shared and co-created, our project not only speaks to the dynamic and multiple ways in which young people articulate their identities, but how they process them — that is to say, develop them. Through our participatory approach, which we now turn to, we gained particular access to the process of identity development.

\section{Process: Fostering a Collaborative Space Through Methods}

Given that Erin is not a member of this cultural community, she is guided by Maori scholar Linda Tuhiwai Smith’s Decolonizing Methodologies (1992). Here, Smith argues for the importance of directly involving Indigenous people in the study of their cultures and outlines a number of practical guidelines for such work, emphasizing the necessity of collaborative approaches, continuous community engagement, and the priority of maintaining Indigenous people’s ownership and control of their cultures. Prior to beginning the reading discussion groups, Erin spent some time getting to know the administrators, students, teachers, and wider community on the Kainai Blood Reserve. We organized a reading field trip, where we took the students to various comic and used book stores, to Chapters, and to the public library. She attended school basketball games, drama productions, and accompanied the school on a trip to 
Waterton Lakes National Park. These outings gave her an opportunity to build rapport with the students, in turn helping to create an ethical space (Ermine, 1995) where there was a shared level of both vulnerability and comfort - much akin to the work done by other scholars within this journal edition, such as Mack and Newberry, Navia, and Hauge. Aboriginal educational theorist Marie Battiste (2013) describes these acts of reciprocity as “imagining what can be as a result of informed ethical engaged effort” (n.p).

We began by reading aloud a selection of books chosen by Andrea and the librarian. During and after the read aloud, the students engaged in a series of participant-led group discussions. While we were present, our role was minimal. We would sometimes prompt a participant to say more, or would ask open-ended questions, such as: What images of place does the text evoke? What is the influence of the setting on your reading of this text? What kind of relationships do the characters have with place? Rather than conceptualizing these events as individual encounters, the communal, dialogical nature of the discussion groups fostered critical readings of and deeper engagement with texts. Through our transactions, across encounters, we came to understand how the participants understood themselves, their families, peers, geographies and their communities in complex, shifting ways. These conversations allowed us to interrogate the ways in which the participants used their readings of the text to engage critically with their own identities and the experiences of their peers.

We chose group discussions as a point of departure, agreeing with Gordon Wells (2000), who, drawing on Lev Vygotsky's theory of learning, writes that “an individual is able to achieve more with assistance than he or she can manage alone” (p. 57). By providing our participants with an opportunity to articulate their thoughts and experiences and to contribute to what were critical, engaging discussions, they had the chance to consider their perceptions of identity, and 
to "clarify [their] own minds, in order to communicate [their] thoughts to another person" (Chambers, 1985, p.142). We found tangible evidence of their developing identities through the transactional process of reading. In sharing their experiences with one another via the text, we argue that their prior conceptualizations were set in motion: We see evidence of their identities developing through this connection, co-construction, and explicit recognition of difference.

Alongside the discussion groups, the participants created journals. We left the decision of how to respond ultimately up to the student, wanting them to share their realities in a way that felt most suitable to their experiences. Geographer Gillian Rose (1993) reminds us that some emotions or responses evade verbal or written expression. Similarly, girlhood studies scholar Claudia Mitchell (2011) advocates for the use of visual methods as a mode of inquiry and selfrepresentation in identity work. We also argue that multimodal methods are particularly important for working with young people as their voices are not always truly “voiced.” Much like the work of Navia and Lindquist in this volume, we wanted to access the voices of young people in a way that felt authentic. Lorraine Young and Hazel Barrett (2001) assert that traditional social science methods "rarely involve children in the research process” (p.14). The journals, by documenting the voices of our participants, required them to share their trajectories in a way that felt most suitable to their experiences. The participants' written narratives, drawings, and comic-style sketches spoke of how our conversations and their reading encounters prompted them to construct and re-construct their identities in particular ways.

Lastly, we conducted semi-structured interviews with each participant. By this time, our extensive field notes and transcriptions had provided us with a strong sense of each individual. Students brought their journals along to the interview, where we were able to corroborate that our understanding was as complete as possible, and that these insights were grounded in their 
voices rather than ours. In the following subsection, we provide an example of a series of moments when we were able to trace the identity of one young reader through her responses to and creation of a range of texts.

\section{“It Might Help Me Explain Things:” Adolescence as a Period of Flux}

During our interview, Erin had the following conversation with a participant, Maggie, whose name has been changed.

Erin: $\quad$ Tell me about what you liked about the Alexie book.

Maggie: $\quad$ I liked that it talked about, um, Natives and, like about [...] his life, and how, like, people treated him. And how he felt about his life [...] on the reserve. I never read anything like that before. He made it seem like it is awesome. It is hard to explain why [pause] exactly, but it made me think about my own life. The emotions and experiences I go through living here. And it is interesting that he wrote a whole book about [pause] only his life. It makes me want to write a book about my life. It might help me explain things about being a teenager living here.

Reading about Junior's life on the reserve prompted Maggie to think about the possibility of telling her own story, and how difficult that process might be - especially as an adolescent. She likes that Alexie is writing “about Natives," explaining that she has never "read anything” from that perspective before. While she is attracted to this perspective, her use of the phrase “"made it seem” suggests that Junior’s version of reserve life does not match her own interpretation. Her emphasis on his and my reiterate this difference. Reading about Junior's struggles incites her to reflect on her own life on the reserve, which is presumably not as “awesome.” Maggie’s critical reading capacities allowed her to understand that the vision of reserve life presented within Alexie’s text were not necessarily the same as her own.

Later in our interview, Maggie returned to the idea of writing her own story:

Maggie: If you are a kid, it is easier to write [pause] about childhood. But when you are a teen, you have to write about weird emotions, and you are growing [pause] growing up at the same time. So, uhm, what do you write 
about, when nothing stays the same? And you are ready to become an adult. Well, you are an adult, but you are a teenager. Uhm, and I could say that when you are a teen, things are a little bit difficult but also easy. But when get older you miss being a kid. I miss being a kid.

Erin: What do you miss about it?

Maggie: $\quad$ I had more imagination. Being a teenager is hard [...] especially hard to write about because it is never the same.

Maggie’s thoughts about writing reiterate how she conceptualizes identity. She explains adolescence as "difficult” but also "easy." In other words, it is not a fixed or stagnant period where things remain the same, but is a time of change and flux, intercepted with moments of both ease and difficulty, much like the description of liminality offered by Hogue and Forrest in this collection. Childhood, on the contrary, is conceptualized by Maggie as a time of stability. Maggie’s discourse - the way she flips back and forth between adult and teen -illustrates her own insecure identity. She does not know exactly to which category she belongs.

During our conversation, Maggie reflected on what she does in her spare time. She shared the following:

Maggie: I like reading the Bible a lot. It tells you how you are supposed to be. You aren't supposed to do certain things. It makes you do good things, not bad. And I, like, sometimes I read the book for four hours, or maybe two. I'll read out loud to myself and it gives you a lot of answers. The Alexie text was about my life, in a way [...] but it didn’t, uhm, give me a break from my own life. It made me [...] ask more questions.

When read alongside her description of adolescence (where things are “difficult but also easy”), Maggie's reasoning for reading the Bible becomes clear: It provides her with feelings of safety and guidance. It is didactic, in that its lessons and morals are clearly defined and mostly nonnegotiable. It tells her what to think and do, rather than asking her to make decisions for herself. The Alexie text, however, presents numerous challenges and unanswered questions. Junior's identity struggles are not resolved by the end of the text. Readers are asked to imagine his life as 
a continual struggle between living on reserve and off reserve. In providing a snapshot of her own life, particularly her current state of adolescent flux and uncertainty, the text does not offer Maggie enough creative and critical distance. It likely restates the questions she is seeking answers to, while the Bible takes her away, albeit momentarily.

In her female figure monologue, Maggie wrote about her grandmother, with whom she currently lives with her sisters.

Maggie [writes]: $\quad$ She told us - if anything is bothering you, you come and tell me. I love living with her because its comfortable to be around her it is always clean and warm. Her food always tastes awesome and delicious. She reads a lot of books she has a library in her room. She always makes sure I go to school. She made sure I was always happy, my grandma. When I feel sad, lonely, angry, happy. She takes care of me.

From this passage, it is clear that Maggie is also calmed by the presence of her grandmother, who makes her feel "comfortable.” She reiterates that her grandmother "makes sure” she does certain things. In other words, her grandmother provides her with a degree of certainty and direction during this period of adolescent flux. It is clear from these excerpts that Maggie finds this period of instability troubling.

In a final example, during a discussion group, the following conversation occurred about the following quotation, drawn from a conversation between Junior and his best friend Gordy. While Junior leaves the reserve to attend the all-white school in Reardon, Gordy stays on reserve. He finds it difficult to imagine a future elsewhere, explaining to Junior that, "life is a constant struggle between being an individual and being a member of the community.” Here, we can find parallels with Maggie’s previous reflections about her own life and experience of living on a reserve.

Maggie: $\quad$ I like the part [pause] um, when Gordy explains to Junior that there is a community and then there is you. And it is, um, sometimes not the same 
Spring and Fox

thing. Sometimes you do not see things the same way as someone who is in your family or community sees things. I agree there.

Sage: But Junior [he] does not agree [pause] with Gordy. Junior sees it as the same.

You are part of your community. Your family can’t change.

Taylor: $\quad$ Hmm [pause] the community can’t change. I agree.

Maggie: $\quad$ Yes, it can [pause] I think it can. Think of Junior. He leaves the reserve and makes friends. He is unhappy but he still changes. But he has to leave [pause]. It can't stay the same for him in order for him to be happy. There are no answers on the reserve for Junior.

In this subsection, we have shared Maggie's thoughts about adolescence being a time of turmoil and questioning because of its lack of stability. Clearly Maggie’s worldviews do not always match the ideas of her peers or family ("sometimes you do not see things the same way”). While her grandmother provides her moments of security, she is clearly struggling to answer questions about her own identity. Maggie recognizes herself in Alexie’s depiction of Junior. While she is frustrated about its focus on his story, she still catches glimpses of her own experience through his particular framework. She can identify with Junior's inability to 'get answers' on the reserve. Phrases such as “I think it can” and “you are right” and "but” underscore her awareness that her peers have differing ideas and experiences. In sharing their perceptions of the reserve with one another, via the text, we argue that their prior conceptualizations are set in motion: We see evidence of their identities developing through this connection, co-construction, and explicit recognition of difference.

\section{Concluding Thoughts}

Our small-scale, interpretive project provides insight into the experiences and lives of Blackfoot youth. In offering young people the opportunity to respond to and create a range of multimodal texts, we foregrounded the complexity and diversity of their developing identities. 
Our interdisciplinary theoretical approach moved us away from thinking about identity as fixed or static. Rather, taking the concepts of space as a constantly shifting bundle of trajectories and of reading as a transactional process, and drawing on these combined processes as perspectives from which to analyze our work, allowed for a more multifaceted understanding of the process of identity construction.

The examples included briefly here show evidence of Maggie's identity changing over time, across space, and through a range of experiences. Seeing identity and texts as being formed by the coming together of distinctive trajectories illuminates these readers' connections with the reserve, but also with other places beyond the local, such as where they have gone on holiday, previously lived, or experienced through fiction. Conceptualizing identity as fluid underpinned our own analysis, but it also surfaced within our participants’ responses. These young people perceive their lives as being continually under construction. Their perspectives and responses support a framework of identity development that is transactional, a spiraling movement between text and reader, between reader and place, and thus, rather than static or linear, a rich and unfolding process that changes over time, across space, and through a range of experiences. It is a transformative, liminal state that is always in the process of being made. 
Spring and Fox

\section{References}

Alexie, S. (2012). The Absolutely True Diary of a Part-time Indian. New York, NY: Hachette Book Group.

Battiste, M. (2013). Decolonizing Education: Nourishing the Learning Spirit. Saskatoon, SK: Purich.

Bradford, C. (2007). Unsettling narratives: Postcolonial readings of children's literature. Waterloo, ON: Wilfrid Laurier UP.

Bradford, C. (2010). Reading Indigeneity: The ethics of interpretation and representation. Handbook of Research on Children's and Young Adult Literature (pp. 331-341). Wolf, K. Coats, P. Enciso, \& C. Jenkins (Eds.). New York, NY: Routledge.

Breakwell, G. (1986). Coping with threatened identities. London, UK: Methuen \& Co Ltd.

Chambers, A. (1993). Tell me: Children, reading and talk. Stroud, Kent: Thimble Press.

Comber, B. (2013). Schools as meeting places: Critical and inclusive literacies in changing local environments. Language Arts, 90(5), 361-371.

Comber, B. (2016). Literacy, place, and pedagogies of possibility. London, UK: Routledge.

Cuba, L., \& Hummon, D. M. (1993). A place to call home: identification with dwelling, community, and region. The Sociological Quarterly, 34 (1), 111-131.

Dixon, J., \& Durrheim, K. (2000). Displacing place-identity: a discursive approach to locating self and other. British Journal of Social Psychology, 39, 27-44.

Ermine, W. (1995). Aboriginal epistemology. In J. Barman \& M. Battiste (Eds), First Nations education in Canada: the circle unfolds. Vancouver, BC: UBC Press.

Godinho, S., Woolley, M., Webb, J., \& Winkel, K. (2014). Regenerating Indigenous literacy resourcefulness: A middle school intervention. Literacy Learning: The Middle Years, 22(1) 7-15.

Korteweg, L., Ismel, G. \& Guillet, J. (2010). The stories are the people and the land: Three educators respond to environmental teachings in Indigenous children's literature. Environmental Education Research, 16(3), 331-350.

L'Hirondelle Hill, G. \& McCall, S. (2015). The land we are: Artists and writers unsettle the politics of reconciliation. Winnipeg, MB: Arbeiter Ring Publishing.

Massey, D. (2005). For space. London, UK: Sage.

Massey, D. (1991). A global sense of place. Marxism Today, 35(6), 24-29. 
Mills, K. A., Sunderland, N. \& Davis-Warra, J. (2013). Yarning circles in the literacy classroom. The Reading Teacher, 67(4), 285-289.

Mitchell, C. (2011). Doing visual research. New York, NY: Sage.

Peterson, S. (2016). Research in Canada's northern rural and Indigenous communities: Supporting young children's oral language and writing. The Reading Teacher, 70(3), 383-387.

Rose, G. (1993). Feminism and geography: The limits of geographical knowledge. Cambridge, UK: Polity Press.

Rosenblatt, L. (1978/1994). The reader, the text, the poem: The transactional theory of the literary work. Carbondale, IL: Southern Illinois University Press.

Rosenblatt, L. M. (1938/1995). Literature as exploration (5th ed.). New York, NY: The Modern Language Association of America.

Smith, L. (1992). Decolonizing methodologies: Research and Indigenous peoples. New York, NY: Zed Books.

Spring, E. (2015). Where are you from? Locating the young adult self within and beyond the text.” Journal of Children's Geographies, 14.(3), 356-371.

Spring, E. (2016). The experiences of two migrant readers: Freedom, restriction, and the navigation of adolescent space. Jeunesse: Young People, Texts, Cultures, 8(10), 227-247.

Spring, E. (2017). 'Without manifest, none of the book would have happened:' Place, identity, and the positioning of Canadian adolescent readers as literary critics. Children's Literature in Education, 1-18. DOI: https://doi.org/10.1007/s10583-017-9313-y

Truth and Reconciliation Commission of Canada (2015). "Honouring the truth, reconciling for the future:" Summary of the final report of the Truth and Reconciliation Commission of Canada. http://www.trc.ca/websites/trcinstitution/File/2015/Findings/Calls_to_Action_ English2.pdf

Vowel, C. (2016). Indigenous writes: A guide to First Nations, Métis, and Inuit issues in Canada. Winnipeg, MB: Highwater Press.

Wells, G. (2000). Dialogic inquiry in education: Building on the legacy of Vygotsky. In C. Lee \& P. Smagorinsky (Eds.), Vygotskian perspectives on literacy research: Constructing meaning through collaborative inquiry (pp. 51-85). Cambridge, UK: Cambridge University Press.

Wiltse, L. (2015). Not just 'sunny days': Aboriginal students connect out-of-school literacy resources with school literacy practices. Literacy, 49, 60-68. 
Spring and Fox

Yoon, B., Simpson, A., \& Haag, C. (2010). Assimilation ideology: Critically examining underlying messages in multicultural literature. Journal of Adolescent \& Adult Literacy, 54(2), 109-118.

Young, L. \& Barrett, H. (2001). Adapting visual methods: Action research with Kampala street children. Area, 33(2), 141-150. 